\title{
Inhibition of different histone acetyltransferases (HATs) uncovers transcription-dependent and -independent acetylation-mediated mechanisms in memory formation
}

\author{
Katja Merschbaecher, Lucyna Hatko, Jennifer Folz, and Uli Mueller \\ Department 8.3 Biosciences Zoology/Physiology-Neurobiology, ZHMB (Center of Human and Molecular Biology), \\ Faculty 8 - Natural Science and Technology III, Saarland University, D-66041 Saarbrücken, Germany
}

\begin{abstract}
Acetylation of histones changes the efficiency of the transcription processes and thus contributes to the formation of longterm memory (LTM). In our comparative study, we used two inhibitors to characterize the contribution of different histone acetyl transferases (HATs) to appetitive associative learning in the honeybee. For one we applied garcinol, an inhibitor of the HATs of the p300 (EP300 binding protein)/CBP (CREB-binding protein) family, and the HATs of the PCAF (p300/ CBP-associated factor) family. As comparative agent we applied C646, a specific inhibitor that selectively blocks HATS of the p300/CBP family. Immunochemical analysis reveals differences in histone $\mathrm{H3}$ acetylation in the honeybee brain, in response to the injection of either $\mathrm{C} 646$ or garcinol. Behavioral assessment reveals that the two drugs cause memory impairment of different nature when injected after associative conditioning: processes disturbed by garcinol are annihilated by the established transcription blocker actinomycin D and thus seem to require transcription processes. Actions of C646 are unaltered by actinomycin $D$, and thus seem to be independent of transcription. The outcome of our different approaches as summarized suggests that distinct HATs contribute to different acetylation-mediated processes in memory formation. We further deduce that the acetylation-mediated processes in memory formation comprise transcription-dependent and transcription-independent mechanisms.
\end{abstract}

\begin{abstract}
Short-term memory relies on post-translational protein modifications. The formation of long-term memory (LTM) requires gene expression, in addition. LTM and underlying gene expression are regulated by transcription factors, the recruitment of transcriptional coactivators, and by the chromatin structure itself. Remodeling of chromatin is mediated by DNA methylation and post-translational modifications of histones. In particular, the reversible and dynamic acetylation on the amino-terminal tails of histones has been identified as critical regulator of transcriptional processes in neuronal plasticity and memory formation (Sharma 2010; Lubin et al. 2011; Zovkic et al. 2013). Acetylation is mediated by histone acetyltransferases (HATs), and is reversed by histone deacetylases (HDACs) (Selvi et al. 2010; Haggarty and Tsai 2011). Knockout of transcriptional coactivators with intrinsic HAT activity, such as CBP (CREB-binding protein), p300 (EP300-binding protein), PCAF (p300/CBP-associated factor) leads to an impairment of LTM in aversive and appetitive learning (Oliveira et al. 2007, 2011; Barrett et al. 2011). Accordingly, the knockout of HDACs results in an enhanced LTM (Guan et al. 2009; McQuown and Wood 2011). This picture is supported by studies using pharmacological tools to target different HATs and HDACs (Dekker and Haisma 2009; Bowers et al. 2010; Selvi et al. 2010). Focusing here on the HATs, which have been tested in different invertebrate and mammalian learning paradigms (Marek et al. 2011; Merschbaecher et al. 2012; Zhao et al. 2012; Maddox et al. 2013a,b), it has not been addressed how the different HATs (CBP, p300, PCAF, etc.) contribute to particular mechanisms in memory formation.
\end{abstract}

\section{Corresponding author: uli.mueller@mx.uni-saarland.de}

Article is online at http://www.learnmem.org/cgi/doi/10.1101//m.039438.115.
The vast majority of work deals with acetylation in LTM processes (Sharma 2010; Lubin et al. 2011; Zovkic et al. 2013). Interestingly, manipulation of acetylation-dependent processes by the HAT inhibitor garcinol also affects transient memory in honeybees (Merschbaecher et al. 2012). This transient memory has been shown to be insensitive to the transcription blocker actinomycin D (Grünbaum and Müller 1998; Wüstenberg et al. 1998). Considering this, we assume that acetylation-dependent processes can be found in transcription-dependent as well as in transcription-independent mechanisms.

Employing the two HAT inhibitors, garcinol and C646, we analyzed the role of different HATs in the formation of appetitive olfactory memory in honeybees. Garcinol is a naturally occurring product extracted from the plant Garcinia indica. It inhibits PCAF $\left(\mathrm{IC}_{50} \approx 5 \mu \mathrm{M}\right)$ representatives of the GNAT (Gcn5-related $\mathrm{N}$-acetyltransferase) family and HATS of the p300/CBP family $\left(\mathrm{IC}_{50} \approx 7 \mu \mathrm{M}\right)$ (Balasubramanyam et al. 2004). The second inhibitor, C646, exclusively inhibits HATs of the p300/CBP family $\left(\mathrm{IC}_{50}<1 \mu \mathrm{M}\right)$ (Bowers et al. 2010). To identify transcriptiondependent processes we applied the two inhibitors also in combination with the transcription blocker actinomycin D. Actinomycin D intercalates into DNA and thus impairs transcription (Sobell 1985). Our comparative approach demonstrates that these two HAT inhibitors differ in their effects on histone acetylation and their impact on memory formation. Moreover, coapplication

(C) 2016 Merschbaecher et al. This article is distributed exclusively by Cold Spring Harbor Laboratory Press for the first 12 months after the full-issue publication date (see http://learnmem.cshlp.org/site/misc/terms.xhtml). After 12 months, it is available under a Creative Commons License (AttributionNonCommercial 4.0 International), as described at http://creativecommons .org/licenses/by-nc/4.0/. 
of a general inhibitor of transcription, actinomycin D, uncovers processes mediated by the distinct HATs that differ in their sensitivity to this inhibitor.

\section{Results}

\section{Garcinol and C646 differ in their effects on histone acetylation in the honeybee brain}

HATs are highly conserved between species and the domains essential for inhibitor interaction exist in mammals and invertebrates. This is also true for the amino acids indispensible for the specific interaction between C646 and HATs of the p300/CBP family (Bowers et al. 2010), which are conserved between honeybee and mammals (Fig. 1). Different studies show that p300 and CBP preferentially acetylates lysine 18 of histone H3 (H3K18), while HATS of the PCAF family favor acetylation of H3K9 (Schiltz et al. 1999; Horwitz et al. 2008; Jin et al. 2011). To confirm the different actions of the used HAT inhibitors in honeybees, we measured the levels of H3K9ac and H3K18ac after injection of garcinol or C646. We applied C646 $(10 \mu \mathrm{M})$ and garcinol $(60 \mu \mathrm{M})$ at concentrations and time points that have been used previously (Bowers et al. 2010; Federman et al. 2012; Merschbaecher et al. 2012). Two hours after injection we quantified the relative amount of H3, H3K9ac, and H3K18ac in each of the brains by using the ELISA technique (Fig. 2). The H3 signals did not differ between the groups (Student's $t$-test, garcinol/vehicle: $t=0.25$, $\mathrm{df}=18, P=0.81$; C646/vehicle: $t=0.61, \mathrm{df}=22, P=0.55)$ and thus are used to normalize the H3K9ac and H3K18ac signals in each of the samples. Garcinol causes a significant decrease in the relative acetylation levels of H3K9 (Student's $t$-test, H3K9ac/ H3: $t=2.48, \mathrm{df}=18, P=0.022$ ) and H3K18 (Student's $t$-test, H3K18ac/H3: $t=2.55, \mathrm{df}=18, P=0.02)$. Injection of the $\mathrm{p} 300 /$ CBP-specific inhibitor C646 only decreases the level of H3K18ac (Student's $t$-test, H3K18ac/H3: $t=2.8, \mathrm{df}=22, P=0.04$ ) but not that of H3K9ac/H3: $t=0.25, \mathrm{df}=22, P=0.8$ ). This is in agreement with the observations from mammalian systems and demonstrates the distinct action of garcinol and C646 on HATs and thus acetylation processes in the honeybee brain.

\section{Garcinol and C646 do not affect HDAC activity in the honeybee brain}

HATs and HDACs closely interact with each other and regulate their activities by auto-acetylation, acetylation and deacetylation (Selvi et al. 2010; Valor et al. 2013; Eom et al. 2014). The used HAT inhibitors may thus affect HDAC activity. Since this aspect has not

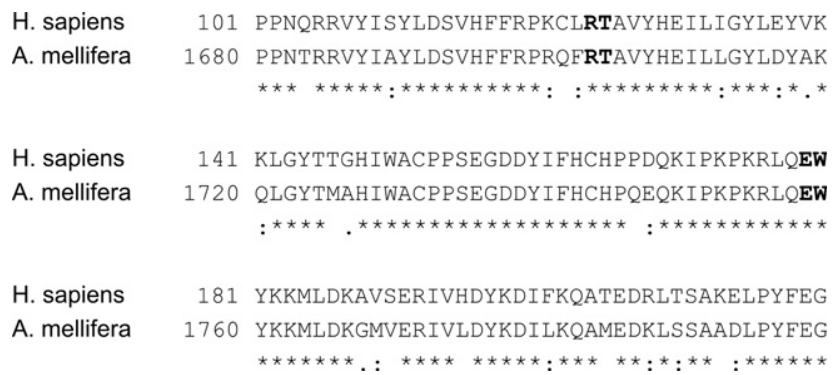

H. sapiens 181 YKKMLDKAVSERIVHDYKDIFKQATEDRLTSAKELPYFEG A. mellifera 1760 YKKMLDKGMVERIVLDYKDILKQAMEDKLSSAADLPYFEG $\star * * * * * * .: * * * * * * * * *: * * * * *: *: * *: * * * * * *$

Figure 1. Alignment of C646 binding site of human p300 and honeybee homologue. Multiple sequence alignment of the acetyl transferase domain of human p300 (3BIY $\mid A)$ ( $H$. sapiens) and honeybee homologue (XP_006568897.1) (A. mellifera) was performed by ClustalO (http ://www.ebi.ac.uk/Tools/msa/clustalo/). The domain of interaction including the amino acids (bold) essential for the specific C646 interaction with p300 is shown.
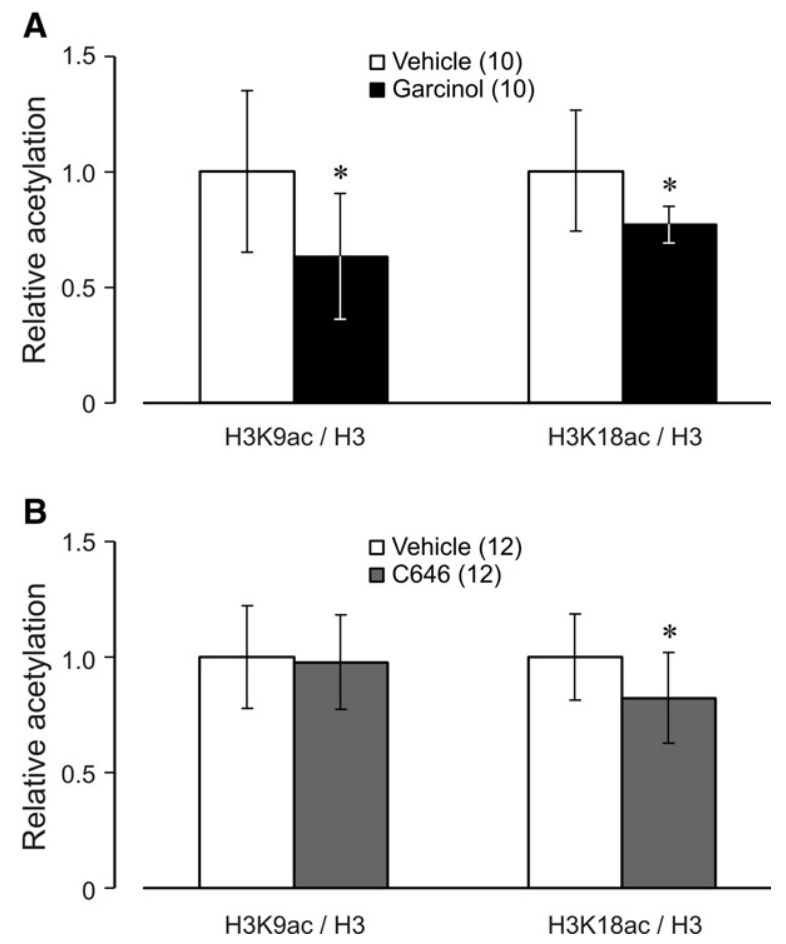

Figure 2. Systemic application of HAT inhibitor C646 or garcinol causes different changes in acetylation at position $\mathrm{H} 3 \mathrm{~K} 9$ and $\mathrm{H} 3 \mathrm{~K} 18$ in honeybee brain. Garcinol $(A)$ or C646 $(B)$ and the vehicle (DMSO) were injected into the hemolymph of honeybees. The central brains without optical lobes were dissected $2 \mathrm{~h}$ after injection and the levels of H3K18ac and $\mathrm{H} 3 \mathrm{~K} 9 \mathrm{ac}$ were quantified and related to the levels of $\mathrm{H} 3$ in each of the samples. After normalization to the corresponding control ratio of a given experiment, the data were pooled and the relative mean $\pm S D$ was calculated. The numbers of animals tested are shown in brackets. Asterisks indicate significant differences (Student's $t$-test (two-tailed); (*) $P<0.05)$ (details in Results).

been addressed in insects we tested for potential effects of garcinol and C646 on HDAC activity in the honeybee brain. The inhibitors were either injected into animals followed by fast brain dissection or added to brain homogenates. The HDAC activities were measured immediately (Table 1 ). To verify the sensitivity of the used HDAC assay we included the HDAC inhibitor TSA (Trichostatin A) as positive control in each of the experiments. As expected, TSA reduces HDAC activity significantly in all setups. This test result legitimates the employed HDAC assay. The HAT inhibitors garcinol and C646 do not affect HDAC activity in the honeybee brain (Table 1). This excludes the possibility that the changes in histone acetylation (Fig. 2) are due to indirect effects of garcinol and C646 on HDAC activities.

\section{HAT inhibitors garcinol and C646 impair different memory phases}

Before analyzing the impact of the HAT inhibitors on appetitive olfactory learning we ensured that C646 and garcinol had no effect on the processing of the sensory stimuli used for associative conditioning (odor and sucrose solution). As test we employed the responsiveness to gustatory stimuli ( $0-1 \mathrm{M}$ sucrose solution) applied to the antennae and in sensitization and habituation tests. As shown in Table 2 neither of the tests showed an effect of injected garcinol or C646, thus excluding an interference of garcinol or C646 with sensory processing or nonassociative learning such as habituation or sensitization. Having found no 
Table 1. HDAC activity in honeybee brain is not affected by HAT inhibitors garcinol or C646

\begin{tabular}{|c|c|c|c|c|}
\hline \multirow[b]{2}{*}{ Application } & \multicolumn{4}{|c|}{ Relative HDAC activity } \\
\hline & Vehicle & $\begin{array}{c}\text { Garcinol (60 } \\
\mu \mathrm{M})\end{array}$ & C646 $(10 \mu \mathrm{M})$ & TSA $(10 \mu \mathrm{M})$ \\
\hline To brain homogenate & $1.00 \pm 0.24(9)$ & $\begin{array}{l}0.93 \pm 0.17(9) \\
P=0.65\end{array}$ & $\begin{array}{l}0.97 \pm 0.21 \\
P=0.68\end{array}$ & $\begin{array}{l}0.08 \pm 0.05(9) \\
P<0.001\end{array}$ \\
\hline $\begin{array}{l}\text { Injection into } \\
\text { hemolymph }\end{array}$ & $1.00 \pm 0.14(10)$ & $\begin{array}{l}0.97 \pm 0.22(12) \\
P=0.78\end{array}$ & $\begin{array}{l}0.89 \pm 0.19(12) \\
P=0.16\end{array}$ & $\begin{array}{l}0.05 \pm 0.01 \\
P<0.01\end{array}$ \\
\hline
\end{tabular}

HDAC activity was determined after adding the indicated drugs to brain homogenate or immediately after brain dissection if honeybees had received hemolymph injection. Final concentration in the homogenate or in the bee (as estimated by body weight) is indicated in brackets. In each of the experiments, the data were normalized with respect to the vehicle (DMSO) control group. The number of tested homogenate samples or injected bees is indicated in brackets. One-way ANOVA: $d f=3, F=60 P<0.001$; Tukey HSD test: TSA-treated group versus each of the other groups $(P<0.01)$. Groups treated with vehicle, garcinol, or C646 do not differ from each other.

unwanted side effects of garcinol or C646 injection, we tested the contribution of garcinol and C646 on associative memory formation. In accordance with all previous studies that addressed the role on memory formation we injected the HAT inhibitors $30 \mathrm{~min}$ after associative conditioning. First we tested the effects of the HAT inhibitors on memory formation after strong associative training (three-trial conditioning). Three-trial conditioning induces a stable LTM (Grünbaum and Müller 1998; Wüstenberg et al. 1998). Garcinol ( $60 \mu \mathrm{M}$ final concentration in the bee) injected 30 min after conditioning does not affect memory tested at $2 \mathrm{~h}$, but drastically reduces memory tested at 1 and $2 \mathrm{~d}$ ( $\chi^{2}$ test, $\left.1 \mathrm{~d}: \mathrm{c} 2=12.9, P=0.0002 ; 2 \mathrm{~d}: \mathrm{c} 2=10.56, P=0.0007\right)$ (Fig. 3A). Likewise injected C646 (10 $\mu \mathrm{M}$ final concentration in the bee) significantly suppresses memory at all measured time points after strong conditioning $\left(\chi^{2}\right.$ test, $2 \mathrm{~h}: \mathrm{c} 2=5.24, P=0.02$; 1 d: $\mathrm{c} 2=10.5, P=0.0008 ; 2 \mathrm{~d}: \mathrm{c} 2=12.84, P=0.0002$ ) (Fig. $3 \mathrm{~B}$ ).

Testing the effects of the HAT inhibitors on memory induced by weak training (single-trial conditioning) reveals further differences between garcinol and C646. Garcinol-injected 30 min after single-trial conditioning only impairs memory tested at $1 \mathrm{~d}$ ( $\chi^{2}$ test, $\mathrm{c} 2=7.32 ; P=0.006$ ), but has no effect on memory tested $2 \mathrm{~h}\left(\chi^{2}\right.$ test, $\left.\mathrm{c} 2=0.01, P=1\right)$ and $2 \mathrm{~d}$ after conditioning $\left(\chi^{2}\right.$ test, c2 $=0.1, P=0.7$ ) (Fig. 4A). C646 injected after single-trial conditioning reduces memory at all times tested $\left(\chi^{2}\right.$ test, $2 \mathrm{~h}: \mathrm{c} 2=4.85$, $P=0.02 ; 1 \mathrm{~d}: \mathrm{c} 2=4.07, P=0.03 ; 2 \mathrm{~d}: \mathrm{c} 2=6.31, P=0.008$ ) (Fig. $4 \mathrm{~B})$ just like it does after three conditioning trials.

\section{Blocking transcription has different effects on memory impairment by garcinol and C646}

Although different, the memory phases affected by the two HAT inhibitors have one feature in common, they are all insensitive to treatment with the transcription blocker actinomycin D (Grünbaum and Müller 1998; Wüstenberg et al. 1998). HATs can also acetylate proteins that are not implicated in transcriptional regulation (Friedmann and Marmorstein 2013). Memory impairments caused by HAT inhibitors could therefore be differently susceptible to actinomycin D treatment. In our respective experiments, we reconfirmed that injection of actinomycin D 30 min after threetrial conditioning does not affect memory tested up to $2 \mathrm{~d}$ (Fig. $5 \mathrm{~A})\left(\chi^{2}\right.$ test, $2 \mathrm{~h}$ : $\mathrm{c} 2=0.04, P=0.84 ; 1 \mathrm{~d}: \mathrm{c} 2=0.03, P=$ $0.86 ; 2$ d: $\mathrm{c} 2=0, P=1$ ). Bees injected with actinomycin $\mathrm{D}$ in a mixture with garcinol show no memory impairment (Fig. 5B) ( $\chi^{2}$ test, vehicle versus garcinol + Act D; $1 \mathrm{~d}$ : $\mathrm{c} 2=0.4, P=0.53$; $2 \mathrm{~d}: \mathrm{c} 2=0, P=1$. Vehicle versus garcinol; $1 \mathrm{~d}: \mathrm{c} 2=10.3, P=0.001 ; 2 \mathrm{~d}: \mathrm{c} 2=$ $5.2, P=0.017)$. Bees injected with C646 in a mixture with actinomycin $\mathrm{D}$ show a similar low performance as bees injected with C646 alone (Fig. 5C) ( $\chi^{2}$ test, vehicle versus $\mathrm{C} 646 ; 2 \mathrm{~h}: \mathrm{c} 2=9.6, P=$ $0.001 ; 1$ d: $\mathrm{c} 2=10.7, P=0.001 ; 2 \mathrm{~d}$ : c2 $=10.9, \quad P=0.001$. Vehicle versus C646 + Act D; 2 h: c2 $=10.9, P=0.001$; $1 \mathrm{~d}: \mathrm{c} 2=16.3, \quad P=0.0001 ; 2 \mathrm{~d}: \quad \mathrm{c} 2=$ 10.9, $P=0.001)$.

Single-trial conditioning again results in a memory different to that caused by three-trial conditioning. In accordance with the aforementioned studies, actinomycin D injection after single-trial conditioning does not affect the memory induced (Fig. 6A) ( $\chi^{2}$ test, 2 h: $\mathrm{c} 2=0.04, P=0.85 ; 1 \mathrm{~d}$ : $\mathrm{c} 2=0.03$, $P=0.86 ; 2$ d: $c 2=0, P=1)$. Nonetheless, injection of actinomycin $\mathrm{D}$ and garcinol in a mixture leaves memory at $1 \mathrm{~d}$ after singletrial conditioning intact, quite in contrast to garcinol alone $\left(\chi^{2}\right.$ test, $1 \mathrm{~d}$ : vehicle versus garcinol, $\mathrm{c} 2=20.5, P=0.001$. Vehicle versus garcinol + Act $\mathrm{D}, \mathrm{c} 2=0.45, P=0.5$ ) (Fig. 6B).

C646 injected in a mixture with actinomycin D leaves bees as memory-impaired ( $\chi^{2}$ test, 2 h: $\mathrm{c} 2=4.4, P=0.02 ; 1 \mathrm{~d}$ : $\mathrm{c} 2=5.9$, $P=0.013 ; 2 \mathrm{~d}: \mathrm{c} 2=6.6, P=0.007)$ as if $\mathrm{C} 646$ was injected alone ( $\chi^{2}$ test, 2 h: $\mathrm{c} 2=4.6, P=0.023 ; 1 \mathrm{~d}$ : $\mathrm{c} 2=5.2, P=0.014 ; 2 \mathrm{~d}$ : $\mathrm{c} 2=5.9, P=0.01$ ) (Fig. 6C). Thus, actinomycin D interferes with the memory impairment caused by garcinol, while the impairing action of C646 is not affected by actinomycin D in both, single- and three-trial conditioning.

\section{Discussion}

By comparing the effects of two different HAT inhibitors on memory formation we demonstrated that: (i) garcinol and C646 affect different memory phases and (ii) when injected in a mixture with actinomycin $\mathrm{D}$, garcinol does not affect memory formation. This does not count for C646. Both findings are new facets of our understanding of memory formation. Previous studies addressed the function of either garcinol or C646 in memory formation (Marek et al. 2011; Merschbaecher et al. 2012; Zhao et al. 2012; Maddox et al. 2013a,b). In mice, injection of garcinol (Maddox et al. 2013a) or C646 (Maddox et al. 2013b) into the amygdala impairs newly acquired as well as reactivated fear memories. Both inhibitors show the same effect in independent studies. They impair memory at $24 \mathrm{~h}$ (LTM) but not at $3 \mathrm{~h}$ (STM), no matter whether

Table 2. HAT inhibitors C646 and garcinol do not affect gustatory responsiveness or nonassociative learning

\begin{tabular}{lrrrr}
\hline Behavioral test & \multicolumn{1}{c}{ Vehicle } & \multicolumn{1}{c}{ C646 } & \multicolumn{1}{c}{ Garcinol } & \\
\hline Gustatory response score & $2.9(35)$ & $2.6(35)$ & $2.6(30)$ & $P>0.4$ \\
Sensitization (PER) & $10 \%(40)$ & $13 \%(40)$ & $8 \%(30)$ & $P>0.9$ \\
Habituation criterion & $24 \pm 12(50)$ & $26 \pm 15(50)$ & $24 \pm 8(30)$ & $P>0.8$ \\
\hline
\end{tabular}

Gustatory responsiveness, sensitization, and habituation were tested $2 \mathrm{~h}$ after injection of garcinol, C646, or vehicle (DMSO). The number of bees tested in the different groups is indicated in brackets. The means of the gustatory response scores do not differ between the groups (Mann-Whitney test). Sensitization is presented as the percentage of animals that elicited the proboscis (PER) to an odor stimulus $15 \mathrm{sec}$ after a sensitizing stimulus $(1 \mathrm{M}$ sucrose) to the antennae. Fisher exact test $(2 \times 3)$ shows no difference. The mean \pm SD of the habituation criterion does not differ between the different groups (Student's $t$-test). 

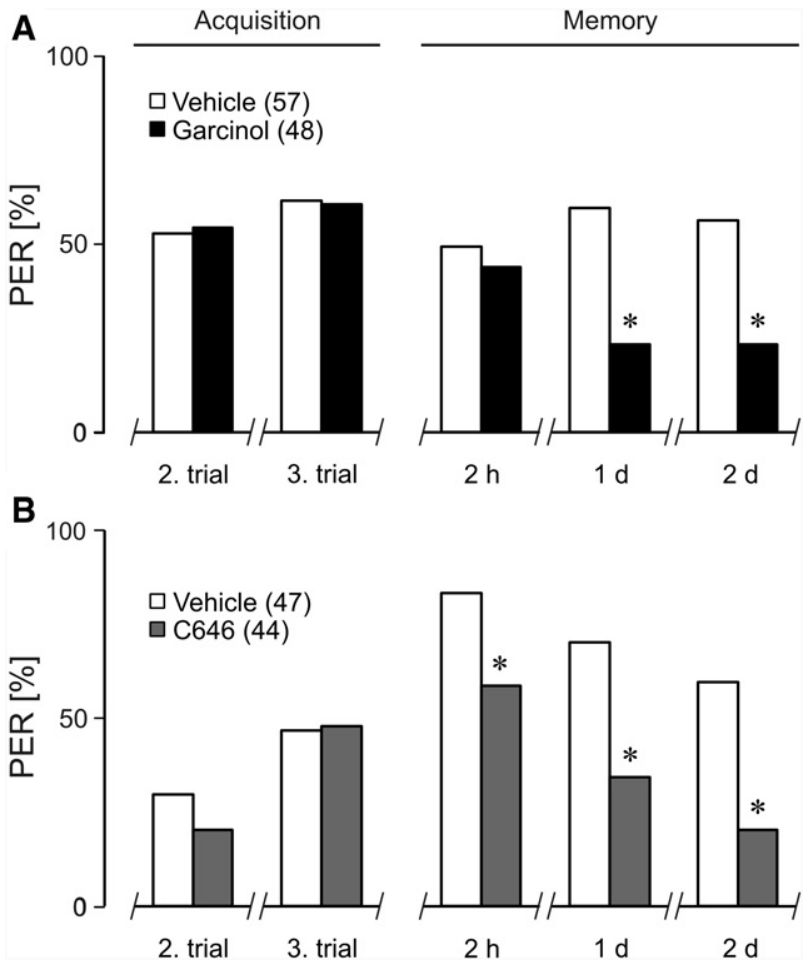

Figure 3. HAT inhibitors garcinol and C646 differently affect memory phases induced by strong associative training. Thirty minutes after strong associative olfactory training (three-trial conditioning) honeybees are injected with garcinol $(A)$, C646 (B), or vehicle (DMSO). The columns represent the percentage of animals that elicit the proboscis (PER, proboscis extension response) during acquisition and retrieval tests at $2 \mathrm{~h}, 1$ and $2 \mathrm{~d}$. The numbers of animals tested in each of the groups is shown in brackets. Asterisks indicate significant differences between treatments as tested for each time point separately (details in Results). Chi-square/Fisher exact test (two-tailed); $\left(^{*}\right) P<0.05$.

tested following conditioning or following memory reactivation. Since both inhibitors act on $\mathrm{p} 300$ and CBP the authors propose a requirement of both in amygdala-dependent fear conditioning.

In our comparative approach we now show that the p300/ CBP inhibitors C646 and garcinol (garcinol also inhibits HATs of the PCAF family) differ in their effects on appetitive associative memory in honeybees, suggesting different functional pathways. Unlike garcinol, C646 causes a memory impairment starting $2 \mathrm{~h}$ after conditioning. The transcription blocker actinomycin D cannot alter this effect, which suggests an implication of cellular processes mediated via acetylation of nonhistone proteins by C646-sensitive p300/CBP.

Studies in different species reveal convincing evidence for a fundamental role of post-translational protein acetylation in basic cellular processes by regulating stability, localization, interaction, and activity of proteins (Choudhary et al. 2009; Spange et al. 2009; Yuan and Marmorstein 2013). Members of the HAT family p300/ CBP sensitive to C646 are known for their role in transcriptional regulation and histone modification. They also acetylate nonhistone substrates (Sadoul et al. 2007; Friedmann and Marmorstein 2013; Valor et al. 2013). However, investigations on the role of protein acetylation, especially on nonhistone targets, are at an early stage. Although not derived from investigations on neuronal plasticity, the list of nonhistone proteins targeted by HATs from the p300/CBP and MYST families (named for the founding members in yeast: MOZ, YBF2, SAS2 and TIP60) contains candidates such as STAT, NF-кB, steroid receptors, importin- $\alpha$. They all con- tribute to processes underlying neuronal plasticity and learning (Nicolas et al. 2013; Srivastava et al. 2013; Snow et al. 2014; Panayotis et al. 2015) and therefore qualify as downstream targets of C646.

Comparatively dealing with garcinol we could contradict the well-documented notion that garcinol-sensitive memory is transcription independent (Grünbaum and Müller 1998; Wüstenberg et al. 1998). Garcinol injected in a mixture with the transcription blocker actinomycin D should, under the known assumption, be impaired as when given pure garcinol. In contrast, we show that when injected with the mixture, bees' learning is enhanced or rescued, independent of single- or three-trial conditioning (Figs. 5, 6). This raises questions regarding the actions of actinomycin $\mathrm{D}$ and garcinol on transcription processes that contribute to memory formation.

Memory formation requires a balanced expression of genes that promote or inhibit synaptic plasticity (Abel et al. 1998; Walkinshaw et al. 2015). Changing the balance toward either promoting or inhibiting genes results in an improved or an impaired memory, respectively. Actinomycin D intercalates into DNA (Sobell 1985), prevents active transcription processes in general, and thus equalizes the imbalance.

In contrast to actinomycin $\mathrm{D}$, the effect of garcinol and other HAT inhibitors on gene expression is more complex. Results derived from cell lines show that, although the majority of differentially expressed genes is downregulated, other genes are upregulated (Balasubramanyam et al. 2004; Gaddis et al. 2015).

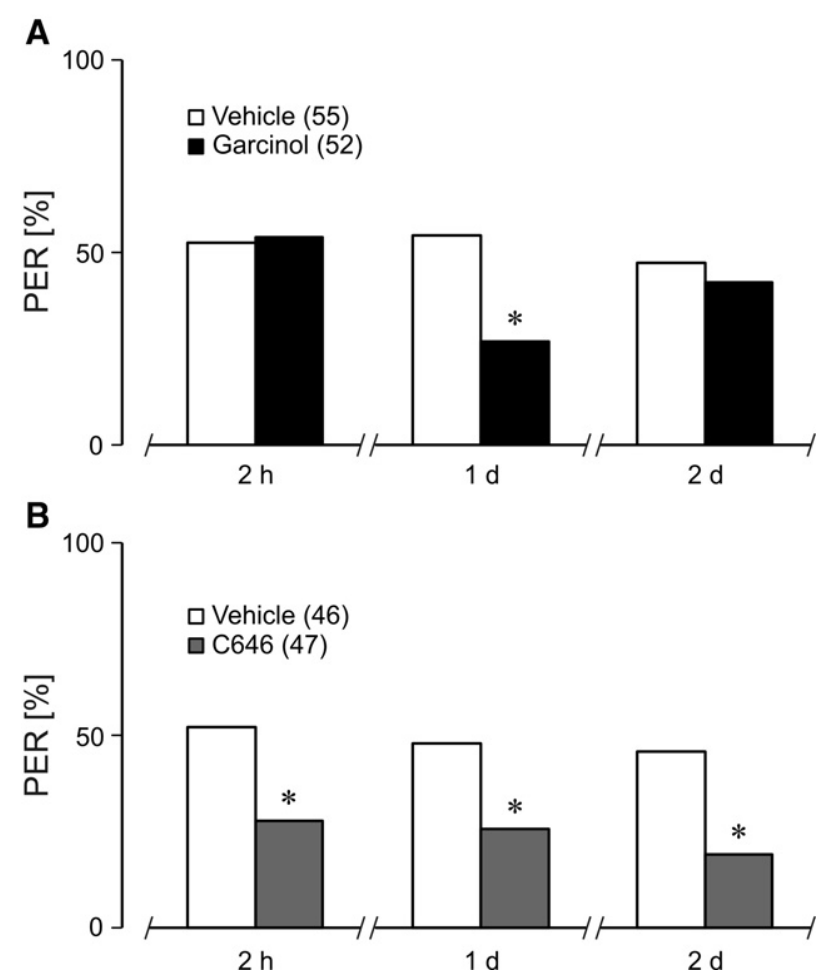

Figure 4. HAT inhibitors garcinol and C646 affect different memory phases after weak training. Honeybees were injected with garcinol $(A)$, C646 (B), or the vehicle (DMSO) 30 min after weak associative training (single-trial conditioning). The columns show the percentage of animals that elicit the proboscis (PER) in the retrieval test at $2 \mathrm{~h}, 1$ and $2 \mathrm{~d}$ after conditioning. The numbers of animals tested in each of the groups is shown in brackets. Asterisks indicate significant differences between treatments as tested for each time point separately (details in Results). Chi-square/Fisher exact test (two-tailed); $\left({ }^{*}\right) P<0.05$. 

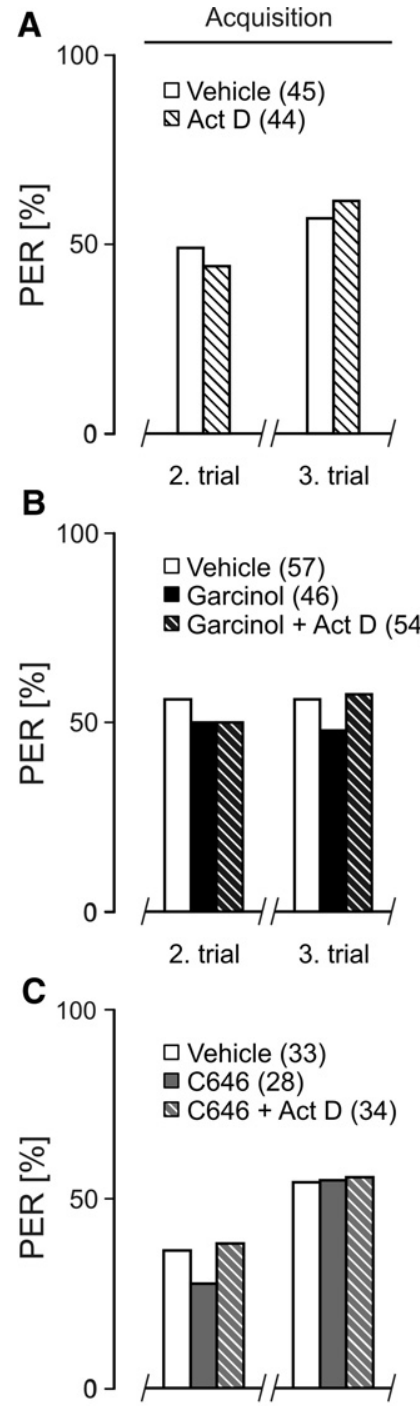

2. trial 3. trial
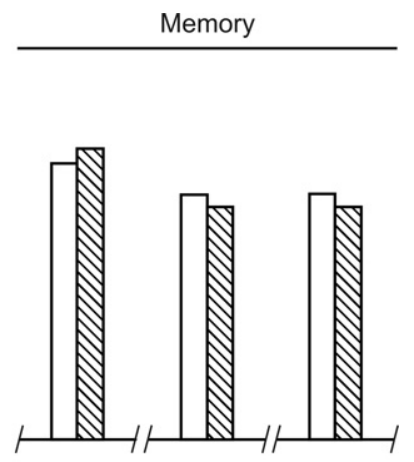

$2 \mathrm{~h} \quad 1 \mathrm{~d} \quad 2 \mathrm{~d}$
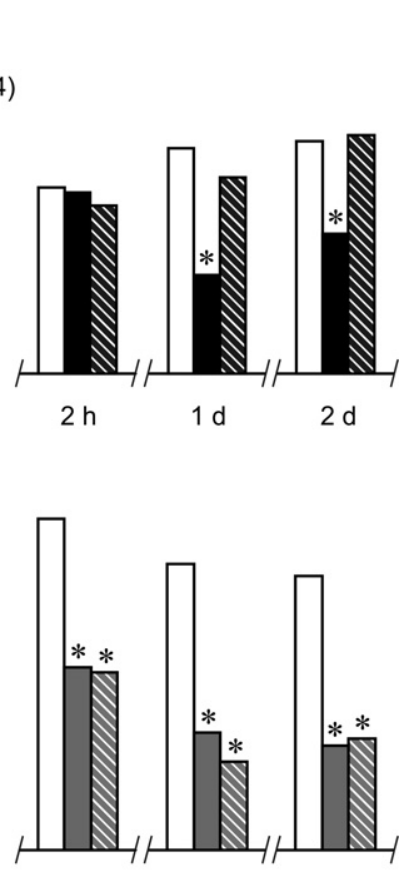

$2 \mathrm{~h} \quad 1 \mathrm{~d} \quad 2 \mathrm{~d}$

Figure 5. Actinomycin $D$ abolishes the effect of garcinol but not that of C646 on memory induced by three-trial conditioning. $(A)$ Injection of actinomycin $D($ Act $D$ ) alone 30 min after three-trial conditioning does not affect memory tested up to $2 \mathrm{~d}$. (B) Injection of actinomycin D together with garcinol abolishes the effects of garcinol on memory at 1 and 2 d. (C) Co-injection of actinomycin D and C646 does not affect C646 induced effects on memory. The columns show the percentage of animals that elicited the proboscis (PER) during acquisition and retrieval tests at the indicated time points. The number of bees tested is shown in brackets. Asterisks indicate significant differences between the groups (details in Results). Chi-square/Fisher exact test (two-tailed); $\left({ }^{*}\right) P<$ 0.025 .

Thus it is feasible that memory impairment caused by garcinol results from an imbalance of genes with promoting and inhibiting functions in memory formation. The imbalance favors expression of inhibitory genes and thus leads to a reduced memory. In this scenario, coapplication of actinomycin D would especially block inhibitory genes, restore the balance, and thus improve memory again.

In summary, the results support the emerging idea that acetylation-mediated mechanisms contribute to processes of memory formation at various levels of regulation. Building a thorough understanding of the acetylation-mediated processes will re- quire more sophisticated tools to characterize the role of the different HATs, HDACs, and their substrates. Techniques that allow one to discriminate the contribution of processes at the transcriptional level in the nucleus from processes in the cytosol, dendrites, and synapses will have to be developed.

\section{Materials and Methods}

\section{Animals}

The experiments were performed in the years 2012 (AprilOctober) and 2013 (February-September) in Saarbrücken, Germany. Bees (Apis mellifera) were collected from at least three different hives of the university apiary to avoid hive-dependent

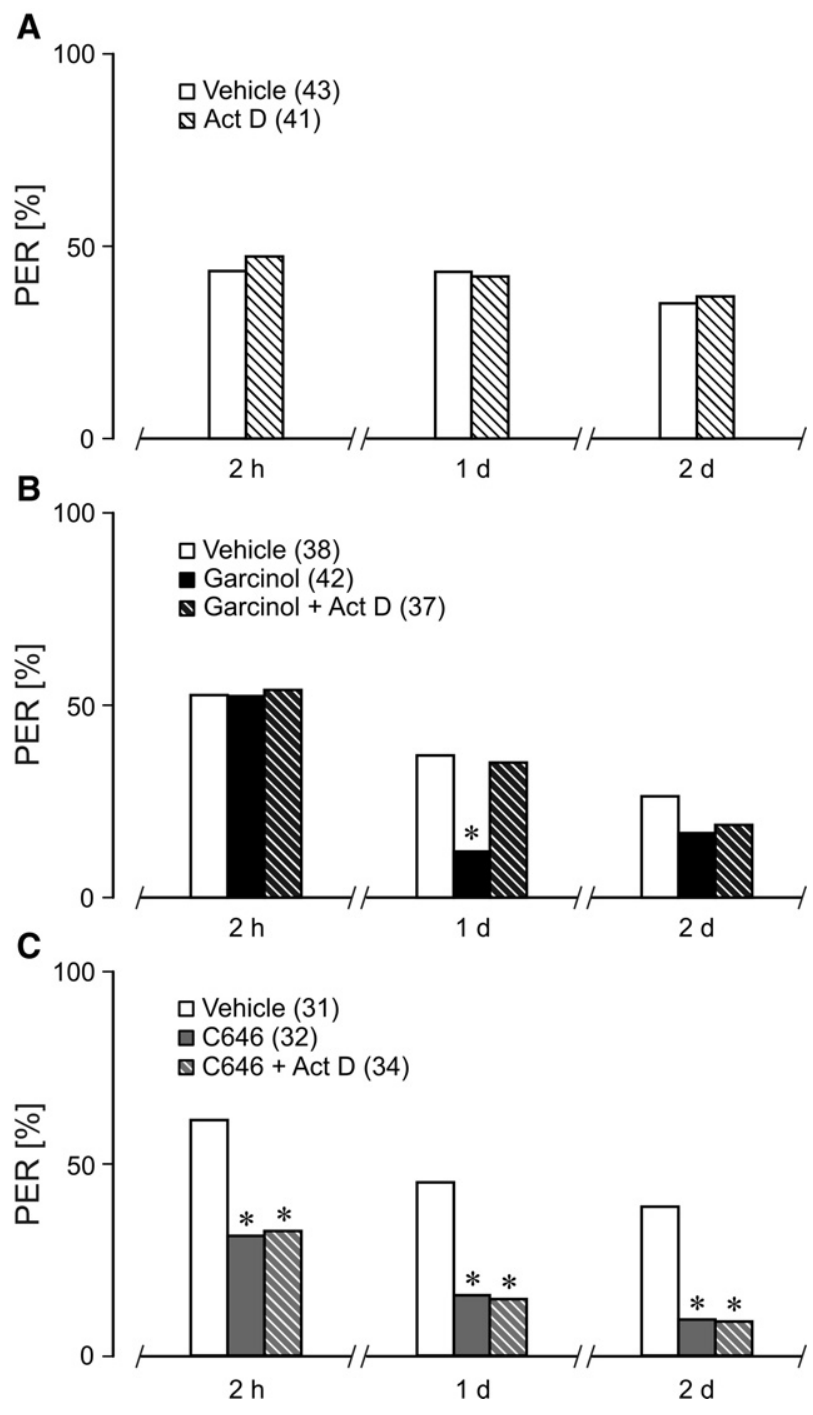

Figure 6. Actinomycin $\mathrm{D}$ abolishes the effect of garcinol but not that of C646 on single-trial induced memory. (A) Injection of actinomycin D (Act D) $30 \mathrm{~min}$ after single-trial conditioning does not affect memory tested up to $2 \mathrm{~d}$. (B) Injection of actinomycin D together with garcinol abolishes the effect on memory at $1 \mathrm{~d}$ induced by garcinol alone. (C) Combined injection of actinomycin D and C646 shows the same effect on memory as C646 alone. The columns show the percentage of animals that elicited the proboscis (PER) in retrieval tests at the indicated time points. The number of bees tested is shown in brackets. Asterisks indicate significant differences between the groups (details in Results). Chi-square/Fisher exact test (two-tailed); $\left(^{*}\right) P<0.025$. 
effects. Foragers were sampled at leaving the hive. After immobilization on ice, the bees were mounted in plastic tubes that allow free movement of the antennae and mouthparts (Grünbaum and Müller 1998; Merschbaecher et al. 2012). Mounted bees were collectively kept in a dark humidity chamber at a relative humidity of $70 \%$ at $20^{\circ} \mathrm{C}-25^{\circ} \mathrm{C}$.

\section{Behavioral analysis}

All behavioral tests were performed according to Merschbaecher et al. (2012). For the gustatory responsiveness test, honeybee foragers were caught on the day of the experiment. They were mounted as described above and fed 2-3 drops of $1 \mathrm{M}$ sucrose solution to just about sustain them until performance. The responsiveness to appetitive stimuli was measured by monitoring the PER after stimulating the antennae with increased sucrose concentrations $(0,30,100,300 \mathrm{mM}$ and $1 \mathrm{M})$ with an interstimulus interval of $2 \mathrm{~min}$. For each bee, the sum of the PER elicited by the five gustatory stimuli represents the gustatory response score $(0-5)$.

For tests involving nonassociative learning (sensitization, habituation) bees were caught and mounted as described above. Sensitization was tested by measuring the PER to an odor stimulus (clove oil) that was applied $15 \mathrm{sec}$ after an acute appetitive stimulus ( $1 \mathrm{M}$ sucrose) to the antennae of hungry bees. Animals showing no PER to the sensitizing sucrose stimulus were excluded from the experiment $(<5 \%)$. For habituation, animals were repeatedly stimulated (1 sec inter-stimulus interval) with $1 \mathrm{M}$ sucrose solution at one antenna only. The number of elicited PER until five consecutive PER failures is defined as habituation criterion. Animals that were not habituated after 50 stimuli were excluded from the analysis $(<5 \%)$. Dishabituation was performed with a sucrose stimulus $(1 \mathrm{M})$ to the contra-lateral antenna following the five consecutive failures. Animals not responding to the dishabituating stimulus were excluded from the analysis $(<5 \%)$.

For associative olfactory conditioning, bees were caught the day before the experiment, mounted, and fed 2-3 drops of $1 \mathrm{M}$ sucrose solution. They were then starved over night for at least $16 \mathrm{~h}$ in a dark humidity chamber at $70 \%$ humidity and $20^{\circ} \mathrm{C}-$ $25^{\circ} \mathrm{C}$. An associative olfactory-conditioning trial consisted of pairing an odor stimulus (conditioned stimulus, CS; clove oil for $5 \mathrm{sec}$ ) with an appetitive reward stimulus (unconditioned stimulus, US; $1 \mathrm{M}$ sucrose for $5 \mathrm{sec}$ ). Animals received either one or three successive conditioning trials with an inter-trial interval of $2 \mathrm{~min}$. Memory was tested $2 \mathrm{~h}, 1$ and $2 \mathrm{~d}$ after training. Animals not responding to the US during conditioning were excluded from the experiment $(<2 \%)$. Two hours after each memory test, the animals were fed 3-4 drops of $1 \mathrm{M}$ sucrose solution.

\section{Drug application}

One microliter of either of the following solutions was injected with a calibrated glass capillary into the hemolymph of the thorax: C646 (cat\#SML0002, Sigma-Aldrich), $1 \mathrm{mM}$ in DMSO; garcinol (cat\#10566, Biomol), $6 \mathrm{mM}$ in DMSO; actinomycin D (cat\#A1410, Sigma Aldrich), $1.8 \mathrm{mM}$ in DMSO, mixture C646/actinomycin $\mathrm{D}(1 \mathrm{mM} / 1.8 \mathrm{mM})$ in DMSO, mixture garcinol/actinomycin D $(6 \mathrm{mM} / 1.8 \mathrm{mM})$ in DMSO. The corresponding control groups were injected with $1 \mu \mathrm{L}$ DMSO only. For the administered in vivo concentration, we assumed a mean bodyweight of 100 $\mathrm{mg} /$ bee.

\section{Quantification of protein acetylation}

To quantify H3K18ac, H3K9ac, and H3 in each of the brain samples we used the enzyme-linked immunosorbent assay (ELISA) (Merschbaecher et al. 2012). Following the described trial sections, honeybees were chilled on ice, the heads were cut off and mounted on wax. The cuticle was opened, the central brain with the mushroom bodies dissected and homogenized in 250 $\mu \mathrm{L}$ homogenization buffer (PBS (137 mM NaCl; $2.7 \mathrm{mM} \mathrm{KCl}$; $10.1 \mathrm{mM} \mathrm{Na}_{2} \mathrm{HPO}_{4} ; 1.8 \mathrm{mM} \mathrm{KH} \mathrm{PO}_{4}$ ) containing $1 \mathrm{mM}$ EDTA and $5 \mathrm{mM}$ sodium butyrate) within $30 \mathrm{sec}$. Each sample was divid- ed onto three separate micro titer plates (F96 Maxisorp, NUNCIMMUNO, Langenselbold, Germany), $50 \mu \mathrm{L}$ aliquot per plate/ antigen. The samples of the different groups within one experiment were placed on the same ELISA plates (separate copy plates for each antibody).

The samples were then diluted in five consecutive steps (1:2) with homogenization buffer. After $1 \mathrm{~h}$ coating, the wells were blocked for $1 \mathrm{~h}$ with blocking buffer (PBS containing 0.5\% BSA) and then incubated for $1 \mathrm{~h}$ at room temperature with the different primary antibodies [anti-acetyl histone H3 (K18) (1:1000) (cat\#SAB4500349, Sigma Aldrich), anti-acetyl histone H3 (K9) (1:1000) (cat\#SAB4500347, Sigma Aldrich), anti-histone H3 (1:5000) (cat\#4499P, Cell signaling), all diluted in PBS containing $0.5 \%$ BSA]. Washing was followed by an incubation with antirabbit IgG alkaline phosphatase conjugated antibody (1:4000 in PBS containing 0.5\% BSA) (cat\#A3687, Sigma Aldrich) for $1 \mathrm{~h}$ at room temperature. For the color reaction phosphatase substrate solution (1 mM 4-nitrophenylphosphate disodium salt (p-NPP) in $0.1 \mathrm{M}$ Tris/ $\mathrm{HCl} \mathrm{pH} 8.7 ; 1 \mathrm{mM} \mathrm{MgCl}_{2}$ ) was added and the conversion of the substrate was quantified with a plate reader (safire ${ }^{2}$, Tecan, Crailsheim, Germany) at $405 \mathrm{~nm}$ using $600 \mathrm{~nm}$ as background.

The ELISA data were evaluated as described previously (Merschbaecher et al. 2012). The slope calculated from the optical density values of the dilution steps represents the relative amount of antigen in a given sample. The means of the relative amounts of H3 did not differ between the groups (Tables 1,2). In each sample, the normalized H3, H3K18ac, and H3K9ac values were used to calculate the H3K18ac/H3 or H3K9ac/H3. After normalization to the corresponding control ratio of a given experiment, the mean $\pm \mathrm{SD}$ was calculated. The two-tailed Student's $t$-test was used to compare the data.

\section{HDAC assay}

The HDAC activity in the honeybee brain was determined using the HDAC Fluorimetric Assay (BML-AK500) (Enzo Life Sciences, Lörrach, Germany) and the AmpliteTM Fluorimetric HDAC Activity Assay Kit, Green Fluorescence (AAT Bioquest, Sunnyvale US). Garcinol, C646, TSA, or DMSO were either added to fresh brain homogenates or injected into the hemolymph $30 \mathrm{~min}$ prior to brain dissection. To quantify the effects of the inhibitors in the homogenates, brains were dissected and homogenized in the buffer provided with the HDAC assays. After splitting each homogenate into four fractions and adding garcinol, C646, TSA, and DMSO, respectively, HDAC assays were performed as described by the suppliers. To analyze the action of the inhibitors in the brain, the HDAC activity was determined after injection of the drugs into the hemolymph. Thirty minutes after systemic injection brains of individual bees are dissected $(<30 \mathrm{sec})$ and subjected to the HDAC assays. The measurements were performed according to the suppliers' instructions. Assay conditions were optimized in pretests and revealed that one-tenth of a honeybee brain in a single measurement is best to determine HDAC activity in the linear range.

\section{Statistical analysis}

SYSTAT10 was used for the statistical analysis. The statistical tests used and the parameters are indicated in in the section results or in the figure legends. $P<0.05$ is considered as significant for the comparison of two groups. If groups are compared twice, the Bonferroni correction was applied and $P<0.025$ is considered as significant.

\section{Acknowledgments}

We thank Angelika Gardezi for excellent technical assistance and Dr. Susanne Meuser for invaluable discussions and comments. 


\section{References}

Abel T, Martin KC, Bartsch D, Kandel ER. 1998. Memory suppressor genes: Inhibitory constraints on the storage of long-term memory. Science 279: $338-341$.

Balasubramanyam K, Altaf M, Varier RA, Swaminathan V, Ravindran A, Sadhale PP, Kundu TK. 2004. Polyisoprenylated benzophenone, garcinol, a natural histone acetyltransferase inhibitor, represses chromatin transcription and alters global gene expression. J Biol Chem 279: $33716-33726$.

Barrett RM, Malvaez M, Kramar E, Matheos DP, Arrizon A, Cabrera SM, Lynch G, Greene RW, Wood MA. 2011. Hippocampal focal knockout of CBP affects specific histone modifications, long-term potentiation, and long-term memory. Neuropsychopharmacology 36: 1545-1556.

Bowers EM, Yan G, Mukherjee C, Orry A, Wang L, Holbert MA, Crump NT, Hazzalin CA, Liszczak G, Yuan H, et al. 2010. Virtual ligand screening of the p300/CBP histone acetyltransferase: Identification of a selective small molecule inhibitor. Chem Biol 17: 471-482.

Choudhary C, Kumar C, Gnad F, Nielsen ML, Rehman M, Walther TC, Olsen JV, Mann M. 2009. Lysine acetylation targets protein complexes and co-regulates major cellular functions. Science 325: 834-840.

Dekker FJ, Haisma HJ. 2009. Histone acetyl transferases as emerging drug targets. Drug Discov Today 14: 942-948.

Eom GH, Nam YS, Oh JG, Choe N, Min HK, Yoo EK, Kang G, Nguyen VH, Min JJ, Kim JK, et al. 2014. Regulation of acetylation of histone deacetylase 2 by p300/CBP-associated factor/histone deacetylase 5 in the development of cardiac hypertrophy. Circ Res 114: 1133-1143.

Federman N, Fustiñana MS, Romano A. 2012. Reconsolidation involves histone acetylation depending on the strength of the memory. Neuroscience 219: 145-156.

Friedmann DR, Marmorstein R. 2013. Structure and mechanism of non-histone protein acetyltransferase enzymes. FEBS J 280: $5570-5581$.

Gaddis M, Gerrard D, Frietze S, Farnham PJ. 2015. Altering cancer transcriptomes using epigenomic inhibitors. Epigenetics Chromatin 8: 9.

Grünbaum L, Müller U. 1998. Induction of a specific olfactory memory leads to a long-lasting activation of protein kinase $\mathrm{C}$ in the antennal lobe of the honeybee. J Neurosci 18: 4384-4392.

Guan JS, Haggarty SJ, Giacometti E, Dannenberg JH, Joseph N, Gao J, Nieland TJ, Zhou Y, Wang X, Mazitschek R, et al. 2009. HDAC2 negatively regulates memory formation and synaptic plasticity. Nature 459: $55-60$.

Haggarty SJ, Tsai LH. 2011. Probing the role of HDACs and mechanisms of chromatin-mediated neuroplasticity. Neurobiol Learn Mem 96: 41-52.

Horwitz GA, Zhang K, McBrian MA, Grunstein M, Kurdistani SK, Berk AJ. 2008. Adenovirus small e1a alters global patterns of histone modification. Science 321: 1084-1085.

Jin Q, Yu LR, Wang L, Zhang Z, Kasper LH, Lee JE, Wang C, Brindle PK, Dent SY, Ge K. 2011. Distinct roles of GCN5/PCAF-mediated H3K9ac and $\mathrm{CBP} / \mathrm{p} 300$-mediated $\mathrm{H} 3 \mathrm{~K} 18 / 27 \mathrm{ac}$ in nuclear receptor transactivation. EMBO J 30: 249-262.

Lubin FD, Gupta S, Parrish RR, Grissom NM, Davis RL. 2011. Epigenetic mechanisms: Critical contributors to long-term memory formation. Neuroscientist 17: 616-632.

Maddox SA, Watts CS, Doyère V, Schafe GE. 2013a. A naturally-occurring histone acetyltransferase inhibitor derived from Garcinia indica impairs newly acquired and reactivated fear memories. PLoS One 8: e54463.

Maddox SA, Watts CS, Schafe GE. 2013b. p300/CBP histone acetyltransferase activity is required for newly acquired and reactivated fear memories in the lateral amygdala. Learn Mem 20: 109-119.

Marek R, Coelho CM, Sullivan RK, Baker-Andresen D, Li X, Ratnu V, Dudley KJ, Meyers D, Mukherjee C, Cole PA, et al. 2011. Paradoxical enhancement of fear extinction memory and synaptic plasticity by inhibition of the histone acetyltransferase p300. J Neurosci 31: $7486-7491$.

McQuown SC, Wood MA. 2011. HDAC3 and the molecular brake pad hypothesis. Neurobiol Learn Mem 96: 27-34.

Merschbaecher K, Haettig J, Mueller U. 2012. Acetylation-mediated suppression of transcription-independent memory: Bidirectional modulation of memory by acetylation. PLoS One 7: e45131.

Nicolas CS, Amici M, Bortolotto ZA, Doherty A, Csaba Z, Fafouri A, Dournaud P, Gressens P, Collingridge GL, Peineau S. 2013. The role of JAK-STAT signaling within the CNS. JAKSTAT 2: e22925.

Oliveira AM, Wood MA, McDonough CB, Abel T. 2007. Transgenic mice expressing an inhibitory truncated form of p300 exhibit long-term memory deficits. Learn Mem 14: 564-572.

Oliveira AM, Estévez MA, Hawk JD, Grimes S, Brindle PK, Abel T. 2011. Subregion-specific p300 conditional-out mice exhibit long-term memory impairments. Learn Mem 18: 161-169.

Panayotis N, Karpova A, Kreutz MR, Fainzilber M. 2015. Macromolecular transport in synapse to nucleus communication. Trends Neurosci 38: 108-116.

Sadoul K, Boyault C, Pabion M, Khochbin S. 2007. Regulation of protein turnover by acetyltransferases and deacetylases. Biochimie 90: 306-312.

Schiltz RL, Mizzen CA, Vassilev A, Cook RG, Allis CD, Nakatani Y. 1999. Overlapping but distinct patterns of histone acetylation by the human coactivators p300 and PCAF within nucleosomal substrates. J Biol Chem 274: $1189-1192$.

Selvi BR, Cassel JC, Kundu TK, Boutillier AL. 2010. Tuning acetylation levels with HAT activators: Therapeutic strategy in neurodegenerative diseases. Biochim Biophys Acta 1799: 840-853.

Sharma SK. 2010. Protein acetylation in synaptic plasticity and memory. Neurosci Biobehav Rev 34: 1234-1240.

Snow WM, Stoesz BM, Kelly DM, Albensi BC. 2014. Roles for NF-кB and gene targets of NF- $\mathrm{B}$ in synaptic plasticity, memory, and navigation. Mol Neurobiol 49: 757-770.

Sobell H. 1985. Actinomycin and DNA transcription. Proc Natl Acad Sci 82: $5328-5331$.

Spange S, Wagner T, Heinzel T, Krämer OH. 2009. Acetylation of non-histone proteins modulates cellular signalling at multiple levels. Int J Biochem Cell Biol 41: 185-198.

Srivastava DP, Woolfrey KM, Penzes P. 2013. Insights into rapid modulation of neuroplasticity by brain estrogens. Pharmacol Rev 65: 1318-1350.

Valor LM, Viosca J, Lopez-Atalaya JP, Barco A. 2013. Lysine acetyltransferases CBP and p300 as therapeutic targets in cognitive and neurodegenerative disorders. Curr Pharm 19: 5051-5064.

Walkinshaw E, Gai Y, Farkas C, Richter D, Nicholas E, Keleman K, Davis RL. 2015. Identification of genes that promote or inhibit olfactory memory formation in Drosophila. Genetics 199: 1173-1182.

Wüstenberg D, Gerber B, Menzel R. 1998. Short communication: long-but not medium - term retention of olfactory memories in honeybees is impaired by actinomycin D and anisomycin. Eur J Neurosci 10: $2742-2745$.

Yuan H, Marmorstein R. 2013. Histone acetyltransferases: Rising ancient counterparts to protein kinases. Biopolymers 99: 98-111.

Zhao Z, Fan L, Fortress AM, Boulware MI, Frick KM. 2012. Hippocampal histone acetylation regulates object recognition and the estradiol-induced enhancement of object recognition. J Neurosci 32: 2344-2351.

Zovkic IB, Guzman-Karlsson MC, Sweatt JD. 2013. Epigenetic regulation of memory formation and maintenance. Learn Mem 20: 61-74.

Received June 22, 2015; accepted in revised form November 18, 2015. 


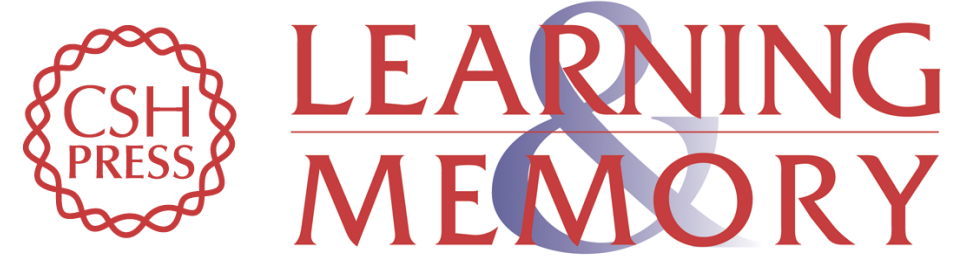

\section{Inhibition of different histone acetyltransferases (HATs) uncovers transcription-dependent and -independent acetylation-mediated mechanisms in memory formation}

Katja Merschbaecher, Lucyna Hatko, Jennifer Folz, et al.

Learn. Mem. 2016, 23:

Access the most recent version at doi:10.1101//m.039438.115

References This article cites 39 articles, 17 of which can be accessed free at: http://learnmem.cshlp.org/content/23/2/83.full.html\#ref-list-1

Creative This article is distributed exclusively by Cold Spring Harbor Laboratory Press for the Commons first 12 months after the full-issue publication date (see

License http://learnmem.cshlp.org/site/misc/terms.xhtml). After 12 months, it is available under a Creative Commons License (Attribution-NonCommercial 4.0 International), as described at http://creativecommons.org/licenses/by-nc/4.0/.

Email Alerting Receive free email alerts when new articles cite this article - sign up in the box at the Service top right corner of the article or click here. 